See discussions, stats, and author profiles for this publication at: https://www.researchgate.net/publication/226097608

\title{
Proposing a Formalised Model for Mindful Information Systems Offshoring
}

Chapter $\cdot$ September 2009

Dol: 10.1007/b137171_50

\section{CITATIONS}

0

4 authors:

E. Gabriel J. Costello

Galway-Mayo Institute of Technology

78 PUBLICATIONS 66 CITATIONS

SEE PROFILE

(a)

Brian Donnellan

National University of Ireland, Maynooth

125 PUBLICATIONS 679 CITATIONS

SEE PROFILE
Chris Coughlan

Hewlett Packard Enterprise

2 PUBLICATIONS OCITATIONS

SEE PROFILE

Andreas Gadatsch

Hochschule Bonn-Rhein-Sieg

173 PUBLICATIONS 234 CITATIONS

SEE PROFILE

Some of the authors of this publication are also working on these related projects:

Research Methods View project

Project Modernes IT-Management View project 


\title{
Proposing a Formalised Model for Mindful Information Systems Offshoring
}

\author{
Gabriel J. Costello ${ }^{1,5}$, Chris Coughlan ${ }^{2}$, Brian Donnellan ${ }^{3}$, Andreas \\ Gadatsch $^{4}$ \\ ${ }^{1}$ Galway-Mayo Institute of Technology, Ireland, gabrielj.costello@gmit.ie \\ ${ }^{2}$ Hewlett-Packard Galway Limited, Ireland, chris.coughlan@hp.com \\ ${ }^{3}$ National University of Ireland, Galway, brian.donnellan@nuigalway.ie \\ ${ }^{4}$ Bonn-Rhein Sieg University of Applied Science, Sankt Augustin, Germany, \\ andreas.gadatsch@fh-bonn-rhein-sieg.de \\ ${ }^{5}$ Centre for Innovation and Structural Change, National University of Ireland, Galway
}

\begin{abstract}
The central thesis of this paper is that Mathematical Economics can provide a novel approach to the examination of offshoring business decisions and provide an impetus for future research in the area. A growing body of research indicates that projected cost savings from IT offshoring projects are not being met. Furthermore, evidence suggests that decision-making processes have been more emotional than rational, and that many offshoring arrangements have been rushed into without adequate analysis of the true costs involved. Building on the concept of mindfulness and mindlessness introduced to the IS literature by Swanson and Ramiller, a cost equation is developed using "deductive reasoning rather than inductive study" in the tradition of mathematical economics. The model endeavours to capture a wide range of both the quantitative and qualitative parameters. Although the economic model is illustrated against the background of a European scenario, the theoretical framework is generic and applicable to organisations in any global location.
\end{abstract}

\section{Introduction}

The central thesis of this paper is that Mathematical Economics can provide a novel approach to the examination of offshoring business decisions and provide an impetus for future research in the area. The description of IT outsourcing performance as "worrying" by Kern \& Willcocks together with the conclusion that most organizations are getting less cost benefits than expected surely calls for some theoretical reflection. Furthermore, cost was one of the six areas identified in their 
2 Costello et al.

research, where companies had experienced severe or difficult problems [1] . This paper argues that more precision is required in IS offshoring decision making given the growing importance of services in the knowledge economy and the resulting value chain re-alignment from selling product to providing integrated customer solutions [2]. Building on the concept of "mindfulness" and "mindlessness" introduced to the IS literature by Swanson and Ramiller [3], a cost model is developed using "deductive reasoning rather than inductive study" in the tradition of mathematical economics. To address the issues of relevance, the theoretical economic model is presented in the context of German companies looking, like the two-headed Janus, to the East and West. These companies are increasingly being driven to offshore IS in order to remain competitive. The focus of the German lens is Ireland, an important location within the European Union for information systems offshoring in software applications, financial services and areas such as call centers and shared services [4]. However, although the economic model is illustrated using a European scenario, the methodology is generic and applicable to organizations in any global location. The paper proceeds as follows: at the outset an overview is given of Ireland as an offshore location in a period of economic transition and following this the business reasons which are driving German companies to offshore IS are presented. A literature review and some theoretical perspectives are then discussed. Subsequently, a formalized economic model is introduced using the approach of mathematical economics that builds on the concept of mindful and mindless decision making. This is followed by a consideration of the variables in the model. Next the implications of the proposed model are discussed and finally suggestions for future research are proposed.

\section{Background and Motivation}

Firstly, the paper will set the scene by providing an overview of Ireland as an offshore location in a time of economic transition and of Germany where a growing number of agencies are being faced with the decision to offshore. The general objective of this opening section is to claim that our economic model follows Chiang's [5] proposition that the development of theory is by its very nature "an abstraction from the real world". Consequently, we initially present the "real world" scenario that provided the impetus for our work and from which the later theoretical framework was abstracted.

\subsection{Offshoring: The Case of Ireland and Germany}

In the closing decades of the twentieth century Ireland leapfrogged from a traditional agrarian economy to a deliberately created information economy [6]. The initial impetus was fuelled by foreign direct investment (FDI) from North Ameri- 
can multi-national corporations (MNCs) setting up offshore manufacturing facilities to avail of low tax incentives, a young educated workforce and proximity to their growing number of European customers. However, this successful model is increasingly being threatened by the low cost economies of Eastern Europe, India and China assertively competing for offshoring and outsourcing business. Irish enterprises rapidly need to build new sources of competitive advantage to sustain employment and standards of living. Ireland is now entering a new era which, according to Michael Porter, requires a transition to an innovation economy [7].

In Germany many companies in the industrial and service sectors- ranging from large corporations to SME (small to medium sized enterprises)- are evaluating how to reduce IT costs by permanently purchasing their IT-Services from countries such as India, China or Eastern Europe; which presently have relatively low labor costs. When looking at the cost of labor only, the German IT-Manager sees an immediate large reduction due to the very high personnel costs at home. However the evidence suggests that many projects cannot achieve these initial over-optimistic financial projections because outsourcing decisions are "much more complicated than expected, have to be reversed, and in some cases lead to failure" [8] .

\subsection{Literature context}

There have been a number of comprehensive reviews of the literature relating to IT outsourcing and offshoring. For example, Dibbern et al. [9] have provided thorough reviews of publications in this area. Their analysis demonstrate that the literature draws from contributions across a wide range of academic fields that encompass traditional economics (production costs), transaction cost economics, institutional theory, theories on social influences, resource dependence theory, psychological contracts, theories on property rights, agency theory, governance inseparability, organizational learning, the resource-based view of the firm and path dependence. Willcocks et al. (2006) identify three distinct phases of publications on outsourcing. In the period from 1991 to 1994 the publications on IT outsourcing were focused on the identification of characteristics regarding firms that outsource. The current era appears to be characterized by a multitude of theories, case work and assertions with little evidence of the emergence of a coherent, comprehensive framework. In light of the rather eclectic landscape of IS offshoring research outlined above, we will argue in the next section that there is a gap for some rigorous theoretical reflection on the subject of IS offshoring. 


\section{Research Framing}

In this section we firstly discuss some theoretical considerations that emerged from the literature review and the academic-practitioner interactions that provided the impetus for our work. Subsequently we introduce the approach of mathematical economics and argue that it can provide a novel lens to enable the development of theory in the area of IS offshoring. In particular, we suggest that the concept of mindfulness, recently proposed to the IS community by Swanson and Ramiller [3], provides a theoretical conceptualization for the deductive development of our offshoring model.

\subsection{Theoretical Considerations}

Many publications have argued that current outsourcing decisions are based on minimalist considerations by purchasing departments [10], insufficient assessment of risk factors [11] and the need to develop multi-dimensional perspectives in an international business context [12]. Models have been developed that simulated offshoring relationships at the country level [13] while Wehrmann \& Gull [14] proposed a decision support model for offshore software development projects using the COCOMO (COnstructive COst MOdel) estimation technique that cosidered cost, effort, and schedule for their emprical study. However, this paper takes a deductive approach and argues that the concepts of mindfulness and mindlessness, proposed by Swanson and Ramiller [3] for decisions on IT innovation; can be profitably applied to decisions on offshoring.

\subsection{Research Approach}

According to Chiang [15] mathematical economics is the application of mathematics to economic analysis through "deductive reasoning rather than inductive study" and as a result principally deals with "theoretical rather than empirical material". More recently, he emphasizes that mathematical economics is an approach to economic analysis and is not a distinct branch of the discipline such as the study of international trade [5]. Also he points out that the main difference of this approach vis-à-vis literary economics is that "assumptions and conclusions are stated in mathematical symbols rather than words; and in equations rather than sentences". Furthermore, Chiang argues that a good theoretical framework "preferably in a mathematical formulation"- is required prior to undertaking any empirical statistical or econometric studies. Mathematical economic equations are characterized by two types of variables [16]: 
- Exogenous variables that are beyond the control of the agents in the model. These variables are also referred to as parameters.

- Endogenous variables that are subject to or determined, directly or indirectly, by agents' choices.

Another important concept in the field is the term "elasticity" where the elasticity of variable $\mathrm{y}$ with respect to another variable $\mathrm{x}$ is "defined as the percentage change in $y$ for a percentage change in x". These concepts will be utilized in the next section where the formalized economic model will be presented.

\section{Towards a Mindful Offshoring Model}

To assist practitioners to guard against "bandwagon" phenomena, a mindless model is first presented. This situation typically results when offshoring strategies have been decided at a senior level in an organization, with little business analysis, and then presented to purchasing department as a fait accompli. Many such corporate directives are committed to work force reduction over short periods of time with an underlying assumption that such actions will lead to cost reductions. The term equation is used interchangeably with the term model in this section of the paper.

\subsection{Mindless Offshoring Equation}

Firstly, a relationship between parameters that express a simplistic cost model for offshoring is developed which is termed a mindless offshoring equation:

$$
T_{\text {OC }}=\sum_{j=1}^{p} Q_{j}\left(L_{j}-R_{j}\right)+\sum_{j=1}^{p} C s_{j} \quad \text { Eq. } 1
$$

where:

$\mathrm{T}_{\mathrm{OC}}=$ total annual cost savings realized by outsourcing to an offshore location

$\mathrm{Qj}=$ annual quantity of product or service of type $\mathrm{j}$

$\mathrm{Lj}=$ local cost (incumbent location) of product or service $\mathrm{j}$

$\mathrm{Rj}=$ offshore (remote) cost of product or service $\mathrm{j}$

$\mathrm{p}=$ total number of products (or services) under consideration for offshoring

Cs = incremental shipping cost to deliver the product: the slowest boat or the telecoms/network with the poorest QoS (Quality of Service) level. and

$\mathrm{Lj}-\mathrm{Rj}=$ the unit cost differential for product (or service) $\mathrm{j}$ between locations. 


\subsection{Mindful offshoring equation}

Secondly, based on the literature referred to above, a relationship is proposed that, we argue, expresses a more realistic cost model for offshoring. This new equation incorporates some of the many costs and business critical factors that are often conveniently ignored when an emotive or mindless decision-making process is pursued.

$$
T^{\prime}{ }_{\text {OC }}=\sum_{j=1}^{p} Q_{j} L_{j}+\sum_{j=1}^{p} C s_{j}^{\prime}-\Omega_{A B}\left(\sum_{j=1}^{p} Q_{j} R_{j}+\sum_{k=1}^{m} C_{k}\right) \quad \text { Eq. } 2
$$

where:

$\mathrm{T}_{\mathrm{OC}}^{\prime}=$ total annual cost savings realized by outsourcing to an offshore location (mindful case)

$\Omega_{\mathrm{AB}}=$ the offshoring coefficient (parametric constant) between local location A and remote location $B$.

$\mathrm{Cs}^{\prime}=$ Differs from $\mathrm{Cs}$ in equation 1 in that a nominal cost (rather than lowest) is used that includes consideration of extra "expediting" costs.

$\mathrm{C}_{\mathrm{k}}=$ additional endogenous variable costs within the firm's locus of control. and

$\mathrm{Lj}-\Omega_{\mathrm{AB}} \mathrm{Rj}=$ the adjusted unit cost differential for product (or service) $\mathrm{j}$ between local location A and remote location B.

Now that we have deductively developed an offshoring model (equation) based on mindful and mindless concepts using the approach of mathematical economics, we will proceed to discuss possible attributes of the parameters and variables. It is proposed that these suggestions can provide the basis for empirical testing and further refinement of the model.

\section{Analysis and Suggestions}

In this section we will firstly discuss possible endogenous variable costs that need to be considered by the firm but that were not included in the mindless equation 1 . Then we will attempt to analyze the offshoring coefficient $\Omega$ in terms of potential constituent parameters. Finally we will evaluate the coefficient intuitively and in terms of the concept of elasticity used in the mathematical economic approach. 


\subsection{Possible Endogenous Variables}

$\mathrm{C}_{\mathrm{k}}$ in equation 2 represent additional endogenous variable costs that are in the control of the firm but which are not considered in the formulation of mindless offshoring models. Here we suggest a number of such costs that could be included in the mindful model that originated from the authors' experience as academics and practitioners in the area.

$\mathrm{C}_{1}=$ vendor assessment costs

$\mathrm{C}_{2}=$ increased auditing costs

$\mathrm{C}_{3}=$ increased local overhead costs per unit due to the transfer resulting in a loss of cost efficiency in the local site.

$\mathrm{C}_{4}$ =increased travel, training, co-ordination and project management costs

$\mathrm{C}_{5}=$ increased warranty costs due to supplier inexperience

$\mathrm{C}_{6}=$ increased cost due to time to market delays

$\mathrm{C}_{7}=$ increased communication cost due to online meetings, telephone calls and e-mail communication (including preparing, reading and executing tasks from e-mails, meetings etc.)

$\mathrm{C}_{8}=$ Management Attention Units (MAU) i.e. the co-ordination overhead costs associated with management having to intervene to ensure that projects are meeting performance and schedule targets

$\mathrm{C}_{9}=$ increased quality costs

\subsection{Offshoring Coefficient}

In equation 2 we introduced the concepts of an offshoring coefficient or parametric constant, $\Omega_{\mathrm{AB}}$, between local location A and remote location $\mathrm{B}$. The purpose of this coefficient is to capture the qualitative attributes that, we argue, need to be taken into account in order to make a mindful offshoring decision. Here we propose that $\Omega_{\mathrm{AB}}$ consists of a number of exogenous variables that are outside the firm's locus of control. Now we will suggest a possible way of capturing these parameters and linking them to the overall offshoring coefficient. Therefore let:

$$
\Omega_{A B}=\prod_{i=1}^{n} \mu_{i}
$$

where $\mu_{1}$ to $\mu_{\mathrm{n}}$ represent the exogenous variables that are outside the control of the firm.

Note: These parameters can be applied to the economic equation such that setting a parameter to 1 indicates a neutral effect. The factors could be estimated in relation to the local location (from where product or service is currently supplied) 
and the proposed remote location. This will also allow a comparison of a number of scenarios in the cost model.

Now we will suggest possible attributes of these parameters.

$\mu_{1}=$ projected labor costs inflation factor for offshore location due to influx of business annualized over a typical 5 or 10 year investment

$\mu_{2}=$ political stability/ instability factor

$\mu_{3}=$ globalization/location attractiveness/ unattractiveness of offshore location where unattractiveness will be expressed as $>1$

$\mu_{4}=$ time zone inefficiency factor

$\mu_{5}=$ risk factor due to theft or piracy; or of losing intellectual property to a supplier becoming a competitor; since both data security and IP protection is a growing concern for companies [17].

$\mu_{6}=$ currency fluctuation risks

$\mu_{7}=$ cultural compatibility factor $F_{1}$ : the cultural compatibility of the offshore company with the parent company.

$\mu_{8}=$ cultural compatibility factor $\mathrm{F}_{2}$ : the cultural compatibility of the offshore company with the customers of the parent company. This is can be very significant in situations such as where the offshore location will provide IT services such as direct customer support.

$\mu_{9}=$ Staff churn rate (taking account of the transient nature of staffing level in offshore locations)

$\mu_{10}=$ Turnaround time or speed of execution of projects

$\mu_{11}=$ Quality of software product or service

\subsection{Elasticity analysis of the equation parameters}

The purpose of this section is to propose a method to test the sensitivity of the qualitative factors $\mu_{1}$ to $\mu_{\mathrm{n}}$ when the estimates are included in an offshoring business decision using the mathematical economic concept of elasticity. We also have a secondary objective to provide some intuitive feel when the concepts are transposed into the empirical domain.

Let the domain of the overall offshoring factor (the product of the individual factors $\mu_{1}$ to $\left.\mu_{\mathrm{n}}\right) \Omega_{\mathrm{AB}}$ be set as follows:

$$
\text { Domain }=\left\{\Omega \mid 0.90^{n} \leq \Omega \leq 1.10^{n}\right\} \quad \text { Eq } 4
$$

Here limits are allocated to the domain from 0.90 to 1.10 .

Let $\mathrm{n}=11$ as in section 5.2; resulting in the minimum and maximum cumulative impact of the factors to be calculated as follows:

$$
\Rightarrow \text { Domain }=\left\{\Omega \mid 0.90^{11} \leq \Omega \leq 1.10^{11}\right\} \quad=>0.31 \leq \Omega \geq 2.85
$$


Note that in this case $n=11$ which assumes that all factors have been estimated. However, in practice, companies can chose to include only the number of these factors that suit their business situation or to set a factor at the neutral level of 1 until further approximations become available internally or externally. Also the formula allows the number of factors to be increased or decreased according to the business requirements. The upper and lower limits above indicate that the maximum effect of applying all the factors $(n=11)$ is to increase or decrease the offshore costing approximately by a factor of three. This analysis of equation 4 results in a first cut approximation that we argue can be used to assist simulation of the elasticity of dependant and independent variables. In this example, the offshoring coefficient $\Omega$ varies with respect to the $\mu$ parameters from $31 \%$ to $285 \%$. Thus equation 4 can test the sensitivity impact on equation 2 of increasing or decreasing the number of factors (n) and their values. Furthermore, in the analysis above, the resulting decrease of the accumulated costs by a maximum of one third raises the intriguing possibility that this equation could be used by companies in the present low-cost zone to reverse-shore IT products or services to higher-cost locations (such as Germany, Ireland, US) because the overall factor analysis indicates that this is the best business decision. Also, similar IT products and services could increasingly originate in the traditional offshore locations and be transferred to the established higher-cost locations as outsourcing companies seek to move up the value chain based on the analysis proposed here.

This section of the paper has attempted to fill the present gap in the financial business case analysis of offshoring decisions by providing a mindful equation that can be built into decision spreadsheets to ensure that managers capture and use realistic figures. Again, as in the previous section, the approach is to provide a tool to assist practitioners make the correct decision rather than providing another mindless solution; where the equation is expected to make the decision by itself.

\section{Discussion}

In the previous two sections we have introduced the concept of a mindful offshoring model and then suggested some attributes of the parameter that could provide further theoretical reflection and empirical investigation. We now discuss some implications and limitations of our work.

\subsection{Assignment of values to the parameters}

The mindful equation contains a large number of parameters some which are typical quantitative financial measurement and some which are of a qualitative kind. We argue that the former can be determined using existing cost management mechanisms and then modeled using a financial spreadsheet to support the com- 
pany level offshoring business decision. For example the vendor assessment cost for an IT offshoring project is quoted in the literature a being of the order of $\$ 500,000[11]$.

An important question at this stage is how to obtain figures for the factors $\mu_{1}$ to $\mu_{\mathrm{n}}$ proposed in the equation and which are in the qualitative category. A number of suggestions to address this include: the company itself could initially provide its own estimates using a cross-functional focus group drawn from expertise within its organisation; it could also utilize existing reputable indices currently available such as the AT Kearney globalisation [18] and location attractiveness indices [17].

\subsection{Implications for Theory and Practice}

This paper argues that the approach of Mathematical Economics provides a novel methodology to contribute to the evaluation of IT investment outsourcing and offshoring-decisions. Furthermore we propose that the offshoring equation developed using the approach has the advantage of generalization and can be iterated and refined by repeated use and updating of the parameters. Hence it has the potential of contributing to the area of offshoring theory. It is also suggested that the logic and reasoning underpinning the equation will open up possibilities for future work in this area. Furthermore we argue that the incorporation of qualitative parameters in the equation is supported by recent evidence on the importance of taking into account factors such as customer relationships when making offshoring decisions.

In the area of practice, Chief Information Officers of many US and European companies are under increasing pressure to reduce their IT-costs. However, outsourcing decisions often seem to be made based on emotion or bandwagon phenomena rather than grounded in factual evidence and based on sound business decision logic. A major obstacle has been the lack of a universally applicable "toolset" to support companies faced with making outsourcing-decisions. Our paper has attempted to address this salient problem.

\subsection{Limitations and Suggestions for Future Work}

This conceptual paper is proposed as a novel theoretical reflection on IS offshoring using the approach of mathematical economics. However there are a number of limitations such as the critique that the contents of the model seem just a "mathematical" listing of practitioner decision making factors that is already amply covered in the literature. Our defense here is that the main contribution of this paper is to introduce the precision inherent in the approach of Mathematical Economics to offshoring research. The attributes of the model were proposed as a starting point in order to facilitate further development both in the areas of complexity and of mathematical operations. Many of the exogenous variables are ex- 
tremely qualitative, for example $\mu_{2}$, and would be difficult to measure or estimate. However as this is a conceptual and theoretical paper we chose to include as many parameters as possible and leave further refinements of the paper open to a wide range of empirical investigation and debate.

Suggestions for future work include investigating other major offshoring locations, such as India or China, to understand whether different endogenous or exogenous parameters apply; or if the equation needs to be localized. In general, the model needs to be moved from the theoretical to the empirical domain to test the underlying propositions and assumptions.

\section{Conclusions}

This paper has argued that the ever increasing demands on IT managers to outsource services to a global marketplace requires economic models to support the decision making process and further develop theory in the field. Consequently we proposed that the precise approach of Mathematical Economics can provide a novel method to examine offshoring business decisions and provide an impetus for future research in the area. This study is the result of an international collaboration, between Germany, where large corporations and increasingly SME are moving a significant portion of IT business to remote locations, and Ireland which is still an important international offshore location. The paper proposed to contribute something novel to the debate by introducing the approach of Mathematical Economics using deductive reasoning in contrast to the prevalent inductive empirical studies that dominate the field. We provided an example of how the methodology could be used to develop a theoretical cost model that replaces the present minimalist business case analysis with a comprehensive equation that captures the wide range of quantitative expenditures and qualitative parameters that must be included in offshoring decision making. Finally the authors suggested that the propositions advanced in this study can promote further work to develop the concepts, both theoretically and practically.

\section{Acknowledgements}

The authors would like to thank the following people for their helpful suggestions during the development of this paper: Deirdre Quin, Lecturer in Mathematics and Clare Lundon Lecturer in Mathematics, Galway-Mayo Institute of Technology; Prof. Dr. Reiner Clement, Professorship of Economics and Innovations, BonnRhein Sieg University of Applied Sciences; John Cullinan, Department of Economics, National University of Ireland, Galway. 


\section{References}

1. Kern, T. and L.P. Willcocks, The relationship advantage: information technologies, sourcing, and management. 2001, Oxford: Oxford University.

2. Grimes, S., Ireland's Emerging Information Economy: Recent Trends and Future Prospects. Regional Studies, 2003. 37(1): p. 3-14.

3. Swanson, E.B. and N.C. Ramiller, Innovating Mindfully with Information Technology. MIS Quarterly 2004. 28(4): p. 553-583

4. Barry, F. and D. van Welsum. Services FDI and Offshoring into Ireland:Panel Session on ICT -enabled offshoring: Country experience and business perspectives. 2005. OECD Committee for Information, Computer and Communications Policy, Paris 9-10 June 2005.

5. Chiang, A.C., Fundamental methods of mathematical economics (4th Edition). Third ed. 2005, Auckland: McGraw-Hill.

6. Trauth, E.M., The Culture of an Information Economy: Influences and Impacts in the Republic of Ireland. 2000, Norwell, MA: Kluwer Academic Publishers.

7. Porter, M., Irish Competitiveness: Entering a New Economic Era, in IMI Top Management Briefing, Dublin, Ireland, 9 October 2003 (available on-line through www.isc.hbs.edu) 2003.

8. Ciborra, C., A Critical Review of the Literature on the Management of the Corporate Information Infrastructure, in From Control to Drift: The Dynamics of Corporate Information Infrastructures, C.U. Ciborra, Editor. 2000, Oxford University Press: Oxford. p. 15-40.

9. Dibbern, J., et al., Information Systems Outsourcing: A Survey and Analysis of the Literature." 35(4): . The Data Base for Adavances in Information Systems 2004. 35(4): p. 6-102.

10. Womack, J.P. and D.T. Jones, Lean thinking: banish waste and create wealth in your corporation. 2003, London: Free Press.

11. Tafti, M.H.A., Risk Factors associated with offshore IT outsourcing. Industrial Management \& Data Systems, 2005. 105(5): p. 549-560.

12. Niederman, F., International business and MIS approaches to multinational organizational research: The case of knowledge transfer and IT workforce outsourcing. Journal of International Management, 2005. 11: p. 187-200.

13. Dutta, A. and R. Roy, Offshore Outsourcing: A Dynamic Causal Model of counteracting Forces. Journal of Management Information Systems, 2005. 22(2): p. 15-35.

14. Wehrmann, A. and D. Gull, Ein COCOMO-basierter Ansatz zur Entscheidungsunterstützung beim Offshoring von Softwareentwicklungsprojekten (A COCOMO-based Approach to Decision Support in Offshoring Software Development Projects).

WIRTSCHAFTSINFORMATIK, 2006. 48: p. 407-417.

15. Chiang, A.C., Fundamental methods of mathematical economics (3rd Edition). Third ed. 1984, Auckland: McGraw-Hill.

16. Baldani, J., J. Bradfield, and R.W. Turner, Mathematical economics. 1996, Fort Worth: Dryden Press.

17. ATK Offshore Index, ATKEARNEY Offshore Location Attractiveness Index: Making Offshore Decisions (available on line at www.atkearney.com ). 2004.

18. ATK Globalisation Index, ATKEARNEY Globalisation Index (available on line at www.atkearney.com ). 2004. 